\title{
FORMULATION AND IN VITRO EVALUATION OF GASTRORETENTIVE FAMOTIDINE HOLLOW MICROSPHERES
}

\author{
G. Lakshmana murthy ${ }^{1}$, Dr. S. Jeevanandham ${ }^{2}$, Dr. G. Prathap Kumar ${ }^{3}$ \\ ${ }^{1}$ Jagans college of Pharmacy, Nellore, Andhrapradesh \\ ${ }^{2}$ Assistant Professor, Department of Pharmaceutics, School of Pharmacy, University of Gondar \\ ${ }^{3}$ M.R.R College of pharmacy, nandigama, Andhrapradesh \\ *Corresponding Author's Email:
}

\begin{abstract}
The main aim of this study is to develop a gastro retentive multiple unit floating drug delivery system for a drug which is poorly absorbed from lower gastrointestinal tract of famotidine. The hollow micro spheres were prepared by the emulsion solvent diffusion technique using eudragit RS 100 as a release rate controlling polymer in the ratios $1: 1,1: 2,1: 3$, and 1:4.The prepared microspheres were evaluated for drug-polymer compatibility, micromeritic properties, drug entrapment efficiency, invitro buoyancy and drug release studies. The mean particle size increased with increase in the polymer concentration. The micromeritic properties were found to be improved when compared to pure drug. Scanning electron microscopy confirmed the hollow structure with smooth external surface. The drug and polymer were found to be compatible as seen in IR studies. The entrapment efficiency of formulation E1-E4 were $70.42 \%, 70.12 \%, 69.22 \%$ and $67.78 \%$ and for the formulation C1-C4 were $72.19 \%, 68.67 \%, 67.14 \%$ and $66.87 \%$, cellulose acetate containing microspheres showed a desirable high drug content and entrapment efficiency respectively. The microspheres floated up to $10 \mathrm{~h}$ over the surface of the gastric buffer medium and the buoyancy percentage was found to be in the range of 60-39\% of E1-E4and C1-C4. In-vitro drug release studies showed that the prepared microspheres exhibited prolonged drug release for more than 12 hours. The mechanism of drug release wasfound to be a combination of both peppas and zero order release kinetics. The developed floating microspheres of aceclofenac may be used for prolonged drug release for at least $12 \mathrm{~h}$ for maximizing the therapeutic efficacy along with patient compliance.

Keywords: Famotidine, Ethyl acetate, acetone, Eudragit RL100, Higuchi's model, PVA, scanning electron microscopy.
\end{abstract}

\section{INTRODUCTION}

Famotidine is a histamine $\mathrm{H}_{2}$-receptor antagonist that inhibits stomach acid production, and it is commonly used in the treatment of peptic ulcer disease (PUD) and gastroesophageal reflux disease (GERD/GORD). It is commonly marketed by Johnson \& Johnson/Merck under the trade names Pepcidine and Pepcid and by Astellas under the trade name Gaster. Unlike cimetidine, the first $\mathrm{H}_{2}$ antagonist, famotidine has no effect on the cytochrome P450 enzyme system, and does not appear to interact with other drugs. ${ }^{1}$

Oral drug administration has been the predominant route for drug delivery. During the past two decades, numerous oral delivery systems have been developed to act as drug reservoirs from which the active substance can be released over a defined period of time at a predetermined and controlled rate. The reasons for this are essentially physiological and usually affected by the GI transit of the form, especially its gastric residence time (GRT), which appears to be one of the major causes of the overall transit time variability. $^{2}$

Gastroretentive floating microspheres are low-density systems that have sufficient buoyancy to float over gastric contents and remain in stomach for prolonged periods. As the system floats over gastric contents, the drug is released slowly at a desired rate resulting in increased gastric retention with reduced fluctuations in the plasma drug concentration. When microspheres come in contact with gastric fluid, the gel formers, polysaccharides, and polymers hydrate to form a colloidal gel barrier that controls the rate of fluid penetration into the device and consequent drug release. As the exterior surface of the dosage form dissolves, the gel layer is maintained by the hydration of the adjacent hydrocolloid layer. The air trapped by the swollen polymer lowers the density and confers buoyancy to the microspheres. However, a minimal gastric content is needed to allow proper achievement of buoyancy ${ }^{3-8}$.

\section{PREFORMULATION STUDIES}

Preformulation testing is an investigation of physical and chemical properties of drug substance alone and when combined with excipients. It is the first step in the rational development of dosage form.

\section{ANALYSIS OF FAMOTIDINE}

Indentification of drug by IR Spectra

The IR spectrum of famotidine in $\mathrm{KBr}$ dispersion was analysed using ABB Bomen model MB 104 Fourier Transform Infrared Spectrophotometer. From the IR spectrum obtained interpretations were made and compared with that of standard. 


\begin{tabular}{|llr|}
\hline Sample Description: FAMOTIDINE & Mode $=2$ (Mid-IR) & DRCEEAL ANALYTTCAL LAB \\
Scans $=20$ & Res $=4 \mathrm{~cm}-1 \quad 20 \mathrm{scans} / \mathrm{min}$ & Apod $=$ Cosine \\
\hline
\end{tabular}

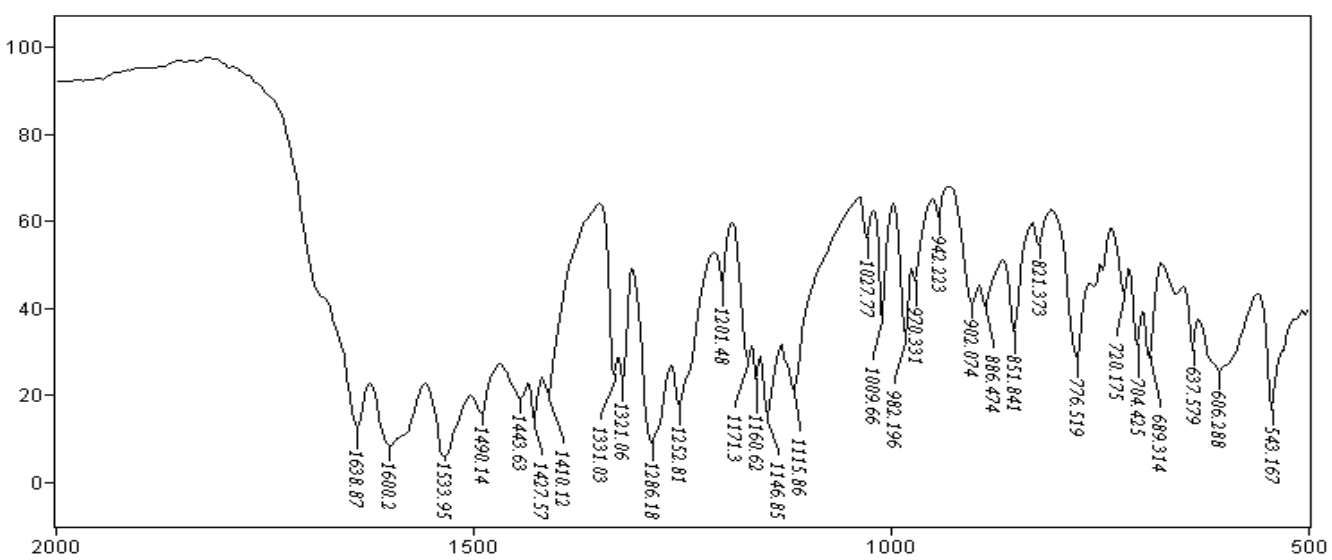

Transmittance / Wavenumber $(\mathrm{cm}-1)$

Figure 1: IR Spectra of Famotidine

\section{Standard calibration of famotidine in $0.1 \mathrm{~N} \mathrm{HCl}$}

\section{Procedure}

In a $100 \mathrm{ml}$ standard flask, stock solution was prepared by dissolving $100 \mathrm{mg}$ of famotidine in $5 \mathrm{ml}$ methanol and made up to the volume with $0.1 \mathrm{~N} \mathrm{HCl}$. From this stock solution $(1 \% \mathrm{w} / \mathrm{v})$, serial dilutions were made by withdrawing $5 \mathrm{ml}, 10 \mathrm{ml}, 15 \mathrm{ml}, 20 \mathrm{ml}$ and $25 \mathrm{ml}$ and transferred individually into $10 \mathrm{ml}$ standard flask and the volume was made up to the mark using $0.1 \mathrm{~N} \mathrm{HCl}$. The absorbance of resulting solutions was measured using shimadzu UV-1601 spectrophotometer at $265 \mathrm{~nm}$ and the values are given in fig 2 .

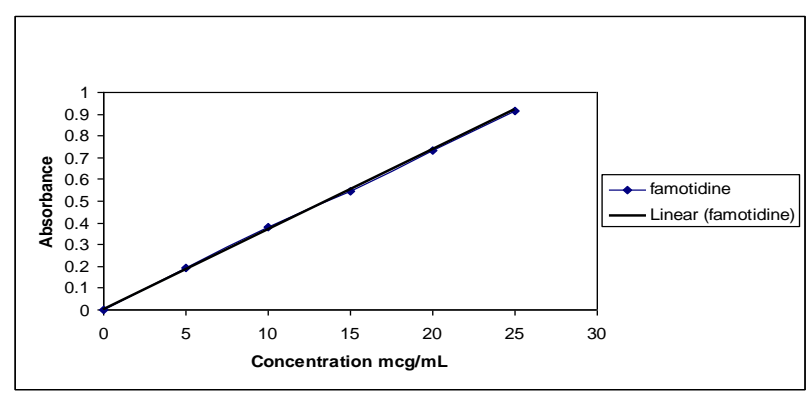

Figure 2: Standard calibration of famotidine in $0.1 \mathrm{~N} \mathrm{HCl}$

\section{MATERIALS AND METHOD: FORMULATION DEVELOPMENT}

Preparation of famotidine floating hollow microspheres using Eudragit RL 100

Microspheres were prepared by emulsion solvent diffusion method'. Four different ratios (E1-E4) of floating hollow microspheres of famotidine were prepared by using Eudragit RL 100 as polymer calculated quantity (as mentioned in table 4) of Eudragit RL 100 and Glyceryl monostearate were dissolved in $20 \mathrm{ml}$ of mixture of ethanol and dichloromethane (1:1) to get a homogenous polymer solution. Famotidine was dispersed uniformly in the polymer solution and then it was poured slowly in to $200 \mathrm{ml}$ of $0.75 \% \mathrm{w} / \mathrm{v}$ polyvinyl alcohol in distilled water. The emulsion formed was stirred continuously for 2 hours using propeller type agitator at $1500 \mathrm{rpm}$. The temperature was maintained at $40^{\circ} \mathrm{C}$. The finely dispersed droplets of the polymer solution of drug were solidified in the aqueous phase via diffusion of the solvent, leaving the cavity of microspheres filled with water. Hollow microspheres formed were filtered using nylon cloth and washed repeatedly with distilled water.

Table 1: (formulation of famotidine floating hollow microspheres E1-E4)

\begin{tabular}{|l|l|l|l|l|l|}
\hline \multirow{2}{*}{ Sl.No. } & \multirow{2}{*}{ Ingredients } & \multicolumn{3}{l|}{ Quantity } \\
\cline { 3 - 7 } & & $\begin{array}{l}\text { E1 } \\
(\mathbf{1 : 1})\end{array}$ & $\begin{array}{l}\text { E2 } \\
(\mathbf{1 : 2})\end{array}$ & $\begin{array}{l}\text { E3 } \\
(\mathbf{1 : 3})\end{array}$ & $\begin{array}{l}\text { E4 } \\
(\mathbf{1 : 4})\end{array}$ \\
\hline 1 & Famotidine & $500 \mathrm{mg}$ & $250 \mathrm{mg}$ & $250 \mathrm{mg}$ & $250 \mathrm{mg}$ \\
\hline 2 & Eudragit RL 100 & $500 \mathrm{mg}$ & $500 \mathrm{mg}$ & $750 \mathrm{mg}$ & $1000 \mathrm{mg}$ \\
\hline 3 & Glyceryl monostearate & $250 \mathrm{mg}$ & $250 \mathrm{mg}$ & $375 \mathrm{mg}$ & $500 \mathrm{mg}$ \\
\hline 4 & Ethanol : Dichloromethane $(1: 1)$ & $20 \mathrm{ml}$ & $20 \mathrm{ml}$ & $20 \mathrm{ml}$ & $20 \mathrm{ml}$ \\
\hline 5 & Polyvinyl Alcohol $(0.75 \% \mathrm{w} / \mathrm{v})$ & $200 \mathrm{ml}$ & $200 \mathrm{ml}$ & $200 \mathrm{ml}$ & $200 \mathrm{ml}$ \\
\hline
\end{tabular}


Preparation of famotidine floating hollow microspehers using cellulose acetate

Four different ratio of (C1 (1:1), C2 (1:2), C3 (1:3), C4 (1:4) ) famotidine floating hollow microspheres were prepared using cellulose acetate were prepared by same procedure as that of Eudragit RL 100. The solvent system used was acetone: ethyl acetate in the ratio of 1:1. Calculated quantities for four different ratios are mentioned in table 2

Table 2: formulation of famotidine floating hollow microspheres C1-C4

\begin{tabular}{|l|l|l|l|l|l|}
\hline \multirow{2}{*}{ S.No. } & \multirow{2}{*}{ Ingredients } & \multicolumn{5}{|c|}{ Quantity } \\
\cline { 3 - 6 } & & $\begin{array}{l}\text { C1 } \\
(\mathbf{1 : 1})\end{array}$ & $\begin{array}{l}\text { C2 } \\
(\mathbf{1 : 2})\end{array}$ & $\begin{array}{l}\text { C3 } \\
(\mathbf{1 : 3})\end{array}$ & $\begin{array}{l}\text { C4 } \\
(\mathbf{1 : 4})\end{array}$ \\
\hline 1 & Famotidine & $500 \mathrm{mg}$ & $250 \mathrm{mg}$ & $250 \mathrm{mg}$ & $250 \mathrm{mg}$ \\
\hline 2 & Cellulose acetate & $500 \mathrm{mg}$ & $500 \mathrm{mg}$ & $750 \mathrm{mg}$ & $1000 \mathrm{mg}$ \\
\hline 3 & Glyceryl monostearate & $250 \mathrm{mg}$ & $250 \mathrm{mg}$ & $375 \mathrm{mg}$ & $500 \mathrm{mg}$ \\
\hline 4 & Acetone : ethyl acetate $(1: 1)$ & $20 \mathrm{ml}$ & $20 \mathrm{ml}$ & $20 \mathrm{ml}$ & $20 \mathrm{ml}$ \\
\hline 5 & Polyvinyl Alcohol $(0.75 \% \mathrm{w} / \mathrm{v})$ & $200 \mathrm{ml}$ & $200 \mathrm{ml}$ & $200 \mathrm{ml}$ & $200 \mathrm{ml}$ \\
\hline
\end{tabular}

\section{CHARACTERIZATION OF MICROSPHERES}

\section{Particle size}

The size distribution in terms of $\mathrm{d}_{(\mathrm{avg})}$ of microspheres of formulations (E1-E4) and (C1-C4) using optical microscopic method with the help of a calibrated ocular micrometer $^{57}$. The results are shown in fig 3 .

\section{Entrapment efficiency}

To determine the entrapment efficiency $50 \mathrm{mg}$ of microspheres was taken in a $50 \mathrm{ml}$ standard flask, $10 \mathrm{ml}$ of methanol was added to solubilize and made up to the volume with distilled water. The drug content was determined by measuring the absorbance at $265 \mathrm{~nm}$ using Shimadzu UV 1601 spectrophotometer.

The percentage drug entrapment efficiency of microspheres were calculated by using the formula
Amount of drug actually present

$\%$ entrapment efficiency $=$ x 100

Theoretical drug load expected

The results are shown in table 4

\section{Buoyancy percentage}

Floating behavior of hollow microspheres was studied in a USP XXIV dissolution apparatus (Type II) by spreading the microspheres (300 mg) on a $0.1 \mathrm{~mol} \mathrm{~L}^{-1} \mathrm{HCl}$ containing $0.02 \%$ between 80 as a surfactant. The medium was agitated with a paddle rotating at $100 \mathrm{rpm}$ and maintained at $37^{\circ} \mathrm{C}$. After $12 \mathrm{hrs}$, both the floating and the settled portions of microspheres were collected separately. The microspheres were dried and weighed. Buoyancy percentage was calculated using the formula.

$$
\% \text { buoyancy of microspheres }=\frac{\text { Weight of buoyant microspheres }}{\text { Initial weight of buoyant microspheres }} \quad \text { x } 100
$$

The results are shown in Table 5.

\section{In vitro drug release study}

The release rate of famotidine from microspheres was determined using USP dissolution testing apparatus I (Basket type). The dissolution test was performed using $900 \mathrm{ml}$ of $0.1 \mathrm{~N} \mathrm{HCl}$, at $37 \pm 0.5^{\circ} \mathrm{C}$ at $100 \mathrm{rpm}^{10}$. Withdrawn samples $(5 \mathrm{ml})$ were analyzed spectrophotometrically at $265 \mathrm{~nm}$. The volume was replenished with the same amount of fresh dissolution fluid each time to maintain the sink condition. All experiments were performed in triplicate. Linear regression was used to analyze the in vitro release mechanism.

\section{Mechanism of drug release}

The in vitro data was treated according to Zero order, First order, Higuchi, Korsmeyer Peppas and Hixson-Crowell equation and the coefficient of correlation was determined.

Zero order Equation - \% released $=$ K.time

First order Equation - log (fraction unreleased $)=K / 2.303$ $x$ time

Higuchi Equation - \% released $=$ K. time 0.5

Korsmeyer Peppas Equation - \%released $=$ K.time $^{n}$

Hixson Crowell Equation- (fraction of unreleased) ${ }^{1 / 3}=1$ K.time

The results are given in Table- 7 and in fig 4

Refabrication and evaluation of selected famotidine floating hollow microspheres 
Microspheres of selected formulations E1-A and C1-A were prepared based on the prototype formulation (E1 and C1) to assess the reproducibility. The method of preparations of E1-A and C1-A were same as that of E1 and $\mathrm{C} 1$ respectively.

Table 3: Refabrication of selected formulations E1-A and C1-A

\begin{tabular}{|l|l|l|l|}
\hline \multirow{2}{*}{ SL. No. } & \multirow{2}{*}{ Ingredients } & Quantity \\
\cline { 3 - 4 } & & E1-A & C1-A \\
\hline 1 & Famotidine & $500 \mathrm{mg}$ & $500 \mathrm{mg}$ \\
\hline 2 & Cellulose Acetate & - & $500 \mathrm{mg}$ \\
\hline 3 & Eudragit RL 100 & $500 \mathrm{mg}$ & - \\
\hline 4 & Glyceryl monostearate & $250 \mathrm{mg}$ & $250 \mathrm{mg}$ \\
\hline 5 & Ethanol : Dichloromethane $(1: 1)$ & $20 \mathrm{ml}$ & - \\
\hline 6 & Ethyl Acetate : Acetone $(1: 1)$ & - & $20 \mathrm{ml}$ \\
\hline 7 & Polyvinyl Alcohol $(0.75 \%)$ & $200 \mathrm{ml}$ & $200 \mathrm{ml}$ \\
\hline
\end{tabular}

Characterization of the Selected Formulations (E1-A and C1-A)

Characteristics of microspheres such as particle size, drug content, entrapment efficiency, percentage buoyancy and in vitro release were evaluated.

\section{MORPHOLOGY: Size and Shape}

The external and internal morphology of the microspheres were studied by scanning electron microscopy (SEM). The samples for SEM were prepared by lightly sprinkling on a double adhesive tape stuck to an aluminum stub. The stubs were then coated with platinum to a thickness of about 10
$\AA$ under an argon atmosphere using a gold sputter module in a high-vacuum evaporator. Afterwards, the stubs containing the coated samples were placed in the scanning electron microscope (JSM-6360A, JEOL, Tokyo, Japan) chamber. The samples were then randomly scanned and photomicrographs were taken at the acceleration voltage of $15 \mathrm{kV}$ to investigate the internal morphology, hollow microspheres were cut with a knife. The SEM photomicrographs of formulations $\mathrm{E} 1-\mathrm{A}$ and $\mathrm{C} 1-\mathrm{A}$ are shown in fig 3.

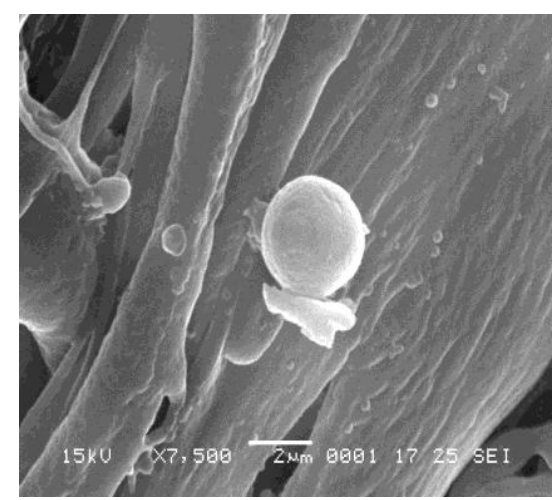

(a)

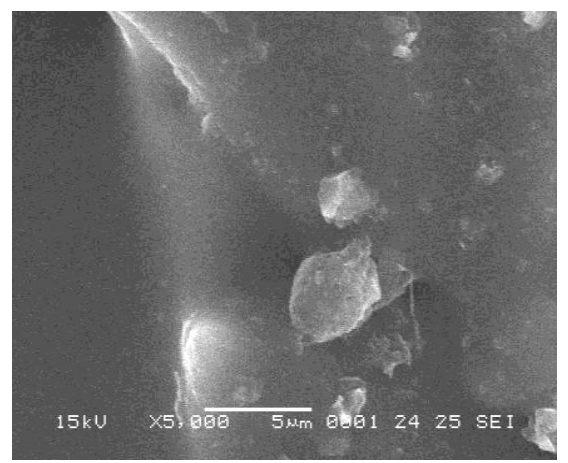

(c)

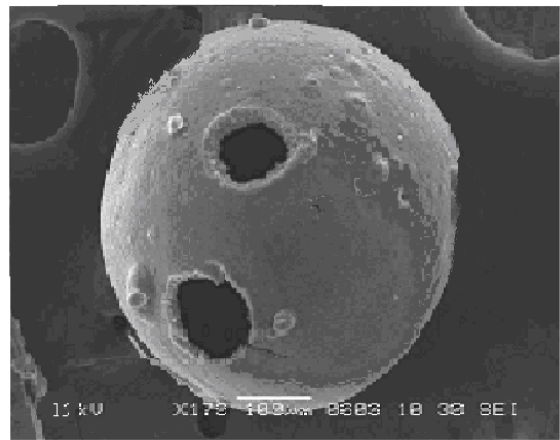

(b)

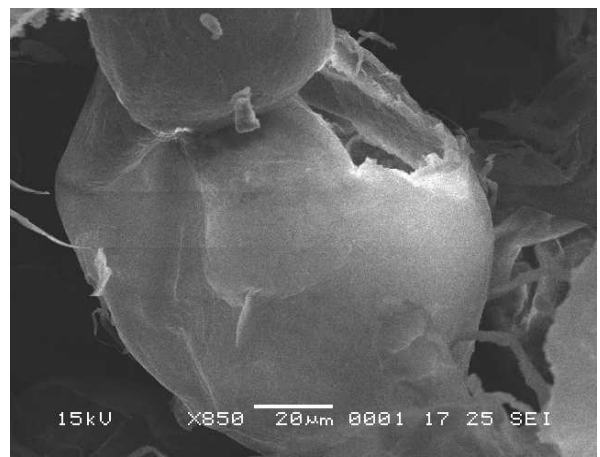

(d)

Figure 3: Scanning electron microphotographs of floating hollow microspheres of famotidine: (a) \& (b) surface and crosssectional morphology of C1-A respectively (c) \& (d) surface and cross-sectional morphology of the formulation E1-A respectively. 
RESULTS:

Characterization of particle size:

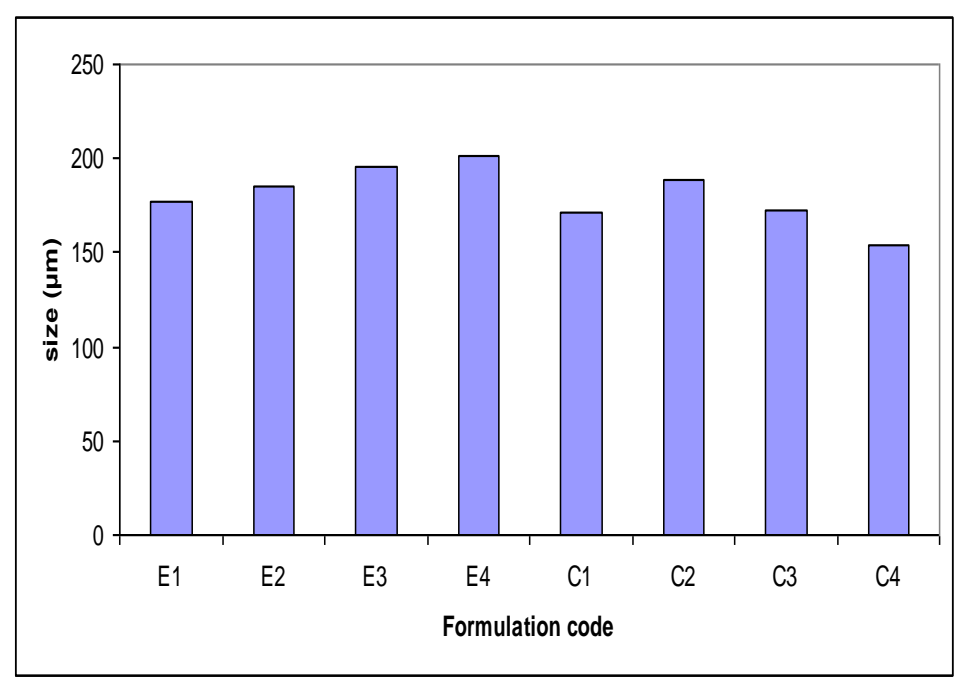

Figure 4: Particle size distribution of formulations E1-E4 and C1-C4

Table 4: Drug entrapment efficiency in formulations (E1-E4 and C1-C4)

\begin{tabular}{|l|l|l|l|l|l|}
\hline \multirow{2}{*}{$\begin{array}{l}\text { SI.No } \\
\cdot\end{array}$} & \multirow{2}{*}{ Formulation code } & \multicolumn{3}{l|}{ Entrapment efficiency $(\boldsymbol{\%})$} & \multirow{2}{*}{ Mean \pm SD } \\
\cline { 3 - 5 } & & $\mathbf{1}$ & $\mathbf{2}$ & $\mathbf{3}$ & \\
\hline 1 & E1 & 71.05 & 70.28 & 69.95 & $70.42 \pm 0.56$ \\
\hline 2 & E2 & 71.2 & 69.18 & 69.98 & $70.12 \pm 1.01$ \\
\hline 3 & E 3 & 69.24 & 70.18 & 68.25 & $69.22 \pm 0.96$ \\
\hline 4 & E 4 & 69.03 & 67.04 & 67.29 & $67.78 \pm 1.08$ \\
\hline 5 & C1 & 72.25 & 71.11 & 73.21 & $72.19 \pm 1.05$ \\
\hline 6 & C2 & 68.98 & 69.01 & 68.64 & $68.87 \pm 0.20$ \\
\hline 7 & C3 & 67.19 & 66.91 & 67.34 & $67.14 \pm 0.21$ \\
\hline 8 & C4 & 67.56 & 66.14 & 66.92 & $66.87 \pm 0.71$ \\
\hline
\end{tabular}

Table 5: Buoyancy percentage of formulations E1-E4 and C1-C4

\begin{tabular}{|c|c|c|c|c|c|}
\hline \multirow{2}{*}{ Sl.No. } & \multirow{2}{*}{ Formulation code } & \multicolumn{3}{|c|}{ Buoyancy (\%) after $12 \mathrm{~h}$} & \multirow{2}{*}{ Mean \pm SD } \\
\hline & & 1 & 2 & 3 & \\
\hline 1 & E1 & 70.17 & 69.11 & 68.36 & $69.21 \pm 0.09$ \\
\hline 2 & E2 & 67.15 & 68.05 & 66.52 & $67.24 \pm 0.76$ \\
\hline 3 & E3 & 66.16 & 67.29 & 65.95 & $66.46 \pm 0.72$ \\
\hline 4 & E4 & 64.29 & 64.64 & 63.99 & $64.30 \pm 0.32$ \\
\hline 5 & $\mathrm{C} 1$ & 71.11 & 70.75 & 71.84 & $71.23 \pm 0.55$ \\
\hline 6 & $\mathrm{C} 2$ & 65.34 & 64.61 & 66.1 & $65.35 \pm 0.74$ \\
\hline 7 & $\mathrm{C} 3$ & 59.26 & 59.97 & 61.21 & $60.14 \pm 0.98$ \\
\hline 8 & $\mathrm{C} 4$ & 58.86 & 59.12 & 60.37 & $59.45 \pm 0.80$ \\
\hline
\end{tabular}


Table 6: In vitro release data

\begin{tabular}{|l|l|l|l|l|l|l|l|}
\hline \multicolumn{7}{|l|}{ In vitro release data of famotidine from the formulationE1,E2,E3,E4\&C1,C2, C3,C4 } \\
\hline E1 & $\mathbf{E 2}$ & $\mathbf{E 3}$ & $\mathbf{C 1}$ & $\mathbf{C 2}$ & $\mathbf{C 3}$ & $\mathbf{C 4}$ \\
\hline $24.32 \pm 0.57$ & $18.57 \pm 0.46$ & $14.46 \pm 0.22$ & $12.87 \pm 0.85$ & $19.74 \pm 0.25$ & $15.66 \pm 0.18$ & $13.26 \pm 0.48$ & $10.39 \pm 0.32$ \\
\hline $26.48 \pm 0.05$ & $21.69 \pm 0.29$ & $18.28 \pm 0.65$ & $13.80 \pm 0.14$ & $22.66 \pm 0.27$ & $19.27 \pm 0.38$ & $15.88 \pm 0.24$ & $12.33 \pm 0.48$ \\
\hline $28.51 \pm 0.23$ & $26.23 \pm 0.17$ & $20.43 \pm 0.61$ & $16.89 \pm 0.26$ & $28.00 \pm 0.23$ & $22.32 \pm 0.83$ & $18.79 \pm 0.69$ & $15.33 \pm 0.71$ \\
\hline $31.53 \pm 0.65$ & $29.95 \pm 0.62$ & $24.57 \pm 0.57$ & $18.99 \pm 0.12$ & $33.23 \pm 0.37$ & $26.69 \pm 0.14$ & $22.15 \pm 0.10$ & $17.93 \pm 0.68$ \\
\hline $34.49 \pm 0.18$ & $32.01 \pm 0.54$ & $28.10 \pm 0.16$ & $20.52 \pm 0.82$ & $37.73 \pm 0.85$ & $30.29 \pm 0.67$ & $26.08 \pm 0.85$ & $20.06 \pm 0.15$ \\
\hline $37.68 \pm 0.54$ & $34.92 \pm 0.23$ & $30.58 \pm 0.68$ & $23.72 \pm 0.17$ & $41.92 \pm 0.44$ & $34.85 \pm 0.64$ & $29.62 \pm 0.32$ & $22.19 \pm 0.74$ \\
\hline $41.45 \pm 0.71$ & $37.70 \pm 0.11$ & $34.63 \pm 0.74$ & $27.57 \pm 0.66$ & $45.30 \pm 0.90$ & $37.77 \pm 0.44$ & $34.02 \pm 0.48$ & $26.51 \pm 0.49$ \\
\hline $44.18 \pm 0.11$ & $41.70 \pm 0.98$ & $36.80 \pm 0.50$ & $29.51 \pm 0.71$ & $49.53 \pm 0.45$ & $41.93 \pm 0.62$ & $37.17 \pm 0.74$ & $30.56 \pm 0.73$ \\
\hline $47.84 \pm 0.47$ & $45.36 \pm 0.41$ & $40.25 \pm 0.40$ & $32.32 \pm 0.52$ & $53.78 \pm 0.21$ & $44.96 \pm 0.93$ & $40.70 \pm 0.87$ & $33.94 \pm 0.73$ \\
\hline $51.10 \pm 0.22$ & $49.39 \pm 0.12$ & $43.08 \pm 0.52$ & $34.36 \pm 0.55$ & $57.64 \pm 0.23$ & $50.03 \pm 0.18$ & $43.25 \pm 0.29$ & $35.87 \pm 0.78$ \\
\hline $62.53 \pm 0.96$ & $50.57 \pm 0.83$ & $45.86 \pm 0.26$ & $36.41 \pm 0.32$ & $63.30 \pm 0.19$ & $52.60 \pm 0.34$ & $47.37 \pm 0.26$ & $39.42 \pm 0.51$ \\
\hline
\end{tabular}

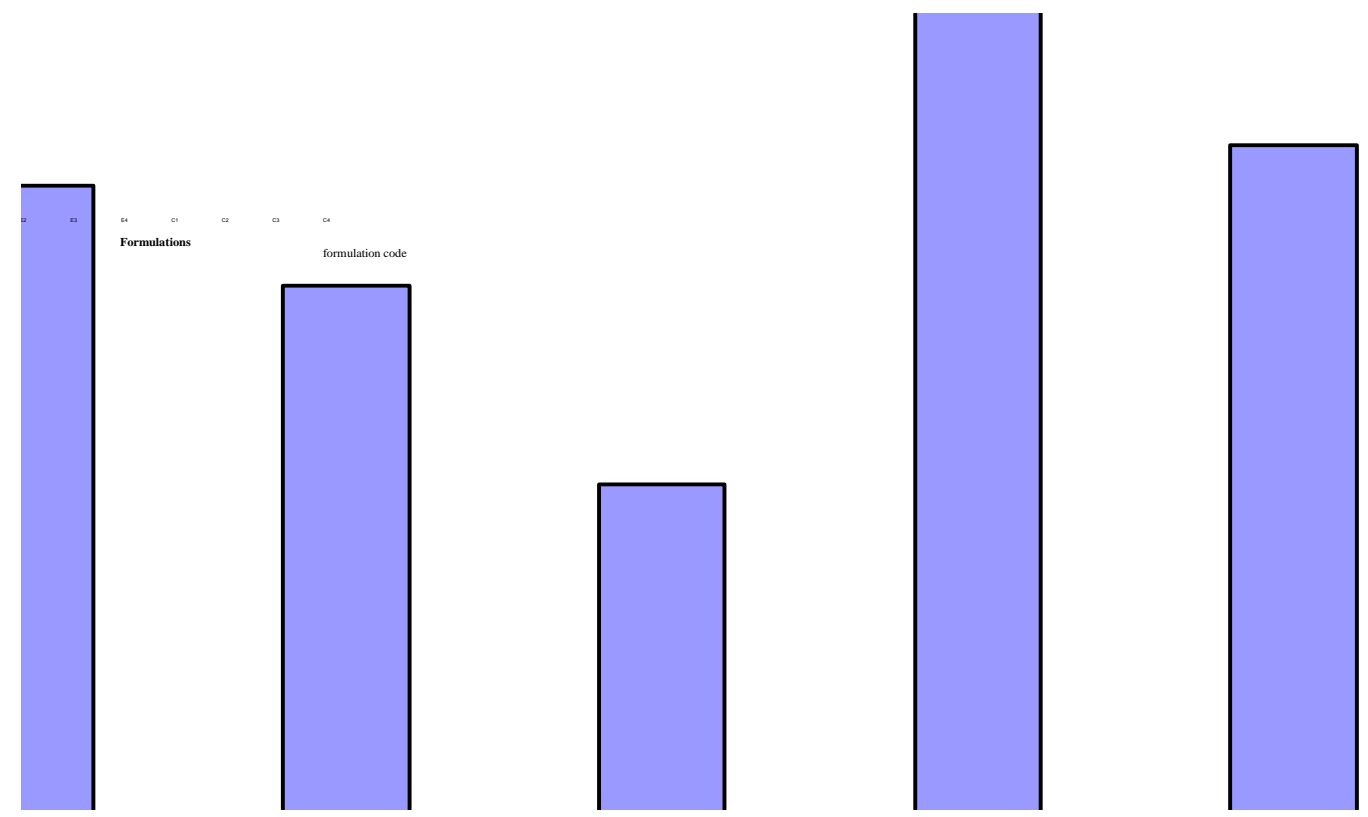

Figure 5: Comparison of in vitro drug release profile of formulations E1-E4 and C1-C4

Table 7: In-vitro kinetics data for formulations E1-E4 and C1-C4

\begin{tabular}{|c|c|c|c|c|c|c|}
\hline \multirow{3}{*}{ Formulation Code } & \multicolumn{6}{|c|}{ Coefficient of correlation $\left(r^{2}\right)$} \\
\hline & \multirow{2}{*}{0 order } & \multirow{2}{*}{$1^{\text {st }}$ order } & \multirow{2}{*}{ Higuchi } & \multicolumn{2}{|c|}{ Korsmeyer Peppas } & \multirow{2}{*}{$\begin{array}{l}\text { Hixson } \\
\text { crowell }\end{array}$} \\
\hline & & & & $\mathbf{r}^{2}$ value & 'n' value & \\
\hline E1 & 0.8585 & 0.9903 & 0.990 & 0.865 & 0.285 & 0.891 \\
\hline E2 & 0.8848 & 0.9407 & 0.974 & 0.966 & 0.337 & 0.9253 \\
\hline E3 & 0.9175 & 0.9579 & 0.986 & 0.968 & 0.384 & 0.9466 \\
\hline E4 & 0.9184 & 0.9486 & 0.974 & 0.932 & 0.365 & 0.9398 \\
\hline C1 & 0.9238 & 0.991 & 0.995 & 0.865 & 0.285 & 0.9612 \\
\hline C2 & 0.9359 & 0.9718 & 0.984 & 0.963 & 0.408 & 0.9631 \\
\hline C3 & 0.9503 & 0.9764 & 0.982 & 0.956 & 0.434 & 0.97 \\
\hline C4 & 0.9585 & 0.9733 & 0.969 & 0.963 & 0.408 & 0.9698 \\
\hline
\end{tabular}


Table 8: Characterization of selected formulations E1-A and C1-A

${ }^{a} \operatorname{Mean} \pm S D, n=3$

\begin{tabular}{|l|l|l|l|}
\hline \multirow{2}{*}{ S.No. } & \multirow{2}{*}{ Parameter } & Observation \\
\cline { 3 - 4 } & & E1-A & C1-A \\
\hline 1 & Mean Particle Size $(\mu \mathrm{m})$ & $171.5 \pm 1.818$ & $165.2 \pm 2.164$ \\
\hline 2 & Entrapment Efficiency $(\%)$ & $70.1 \pm 0.45$ & $72.05 \pm 0.95$ \\
\hline 3 & Buoyancy $(\%)$ & $69.05 \pm 0.15$ & $70.95 \pm 0.35$ \\
\hline
\end{tabular}

Table 9: In vitro release data of famotidine from the formulation E1-A

\begin{tabular}{|c|c|}
\hline $\begin{array}{c}{ }^{\mathrm{a}} \text { Cumulative \% } \\
\text { Drug release }\end{array}$ & $\begin{array}{c}{ }^{\mathrm{a}} \text { Cumulative \% Drug } \\
\text { release }\end{array}$ \\
\hline E1-A & C1-A \\
\hline $24.60 \pm 0.65$ & $19.05 \pm 0.39$ \\
\hline $27.11 \pm 0.52$ & $21.56 \pm 0.11$ \\
\hline $29.15 \pm 0.11$ & $27.30 \pm 0.63$ \\
\hline $32.17 \pm 0.21$ & $32.46 \pm 0.53$ \\
\hline $35.06 \pm 0.36$ & $36.27 \pm 0.99$ \\
\hline $38.33 \pm 0.58$ & $41.34 \pm 0.96$ \\
\hline $41.60 \pm 0.85$ & $44.93 \pm 0.71$ \\
\hline $44.97 \pm 0.39$ & $48.88 \pm 0.62$ \\
\hline $48.84 \pm 0.48$ & $52.99 \pm 0.32$ \\
\hline $51.89 \pm 0.87$ & $57.60 \pm 0.17$ \\
\hline $62.15 \pm 0.43$ & $63.05 \pm 0.76$ \\
\hline
\end{tabular}

In vitro drug release profile of formulations $\mathrm{E} 1-\mathrm{A}$ and C1-A

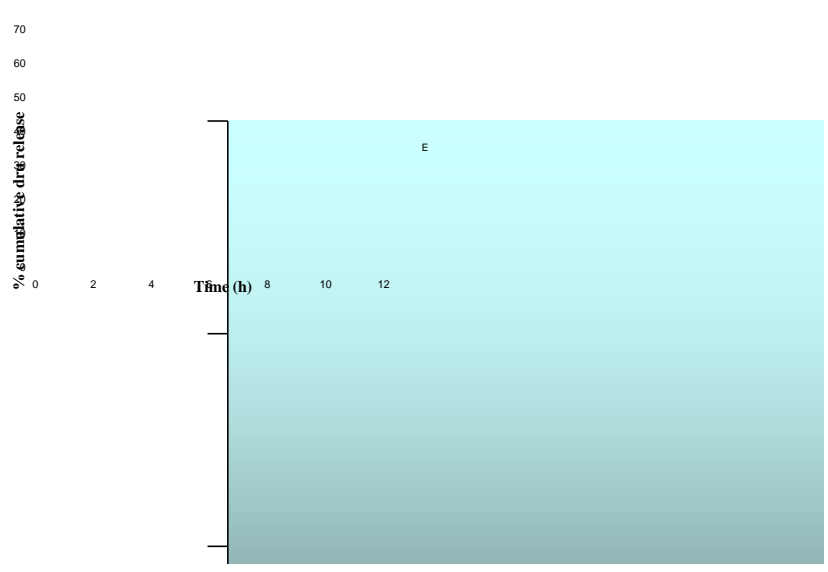

Figure 6: In vitro drug release profile of formulations E1-A and C1-A

Table 10: In vitro kinetics data for refabricated formulations E1-A and C1-A

\begin{tabular}{|c|c|c|c|c|c|c|}
\hline \multirow{3}{*}{ Formulation Code } & \multicolumn{6}{|c|}{ Coefficient of correlation $\left(\mathbf{r}^{2}\right)$} \\
\hline & \multirow{2}{*}{0 order } & \multirow{2}{*}{$1^{\text {st }}$ order } & \multirow{2}{*}{ Higuchi } & \multicolumn{2}{|c|}{ Korsmeyer Peppas } & \multirow{2}{*}{$\begin{array}{l}\text { Hixson } \\
\text { crowell }\end{array}$} \\
\hline & & & & $\mathbf{r}^{2}$ value & 'n' value & \\
\hline E1-A & 0.856 & 0.989 & 0.990 & 0.875 & 0.282 & 0.895 \\
\hline C1-A & 0.935 & 0.988 & 0.991 & 0.980 & 0.422 & 0.968 \\
\hline
\end{tabular}

\section{RESULTS \& DISCUSSION}

The results indicated that the mean particle size or average diameter $\mathrm{d}_{\mathrm{avg}}$ of microspheres was in the range of 153.6201.9. Cellulose acetate polymer containing microspheres were smaller in size than that of Eudragit RL 100 coated microspheres.

The results shown in table 5 indicate the percentage of entrapment efficiency of formulations E1-E4 and C1-C4. The drug content of all formulations was determined spectrophotometrically. The entrapment efficiency of formulation E1-E4 were $70.42 \%, 70.12 \%, 69.22 \%$ and $67.78 \%$ and for the formulation $\mathrm{C} 1-\mathrm{C} 4$ were $72.19 \%$, $68.67 \%, 67.14 \%$ and $66.87 \%$. The results shows cellulose acetate containing microspheres showed a desirable high drug content and entrapment efficiency.

The results shown in table 6 indicate the percentage buoyancy formulations E1-E4 and $\mathrm{C} 1-\mathrm{C} 4$. The percentage buoyancy of formulations E1-E4 at the end of $12 \mathrm{~h}$ were found to be $69.21 \%, 67.24 \%, 66.46 \%$ and $64.3 \%$ and for the formulations $\mathrm{C} 1-\mathrm{C} 4$ at he end of $12 \mathrm{~h}$ were $71.23 \%$,
$65.35 \%, 60.14 \%$ and $59.45 \%$. The results indicates that increase in concentration of polymers, Eudragit RL 100 and cellulose acetate decreases the floating time. Formulation $\mathrm{C} 1$ of cellulose acetate coated microspheres and E1 of Eudragit RL 100 coated microspheres were found to be best.

The results shown in table 7 indicate the in vitro drug release data of formulations E1-E4 and C1-C4. The cumulative percentage drug release of E1-E4 at the end of $10 \mathrm{~h}$ were $62.53 \%, 50.64 \%, 45.86 \%$ and $36.41 \%$ it indicates that increase in concentration of Eudragit RL 100 decreases the release rate of drug. The cumulative drug release of $\mathrm{C} 1-\mathrm{C} 4$ at the end of $10 \mathrm{~h}$ was $63.30 \%, 52.60 \%$, $47.37 \%$ and $39.42 \%$. Increase in concentration of cellulose acetate tends to control the release of famotidine from the formulations.

The data obtained for in vitro release were fitted in to equations for the zero order, first order and Higuchi release models. The interpretation of data was based on the value of the resulting regression coefficient. The in vitro drug 
release showed the highest regression coefficient values for Higuchi's model, indicating diffusion to be the predominant mechanism of drug release. The formulation E1 and C1 using Eudragit RL 100 and cellulose acetate respectively showed constant rate of release and hence these two formulations were chosen as best and refabricated table no 8 .

The results shown in table 9 , indicate the $\mathrm{d}_{(\mathrm{avg})}$ of microspheres of formulations E1-A and C1-A were found to be $171.5 \mu \mathrm{m}$ and $165.2 \mu \mathrm{m}$ respectively. The percentage entrapped and buoyancy percentage after $12 \mathrm{~h}$ were found to be $70.1 \%$ (E1-A), $72.05 \%$ (C1-A) and $69.05 \%$ (E1-A),

\section{REFERENCES}

1. Humphries TJ, Merritt GJ (August 1999). "Review article: drug interactions with agents used to treat acid-related diseases". Aliment. Pharmacol. Ther. 13 Suppl 3;18-26.

2. Aulton ME. In: Pharmaceutics: The Science of Dosage Form Design. 2nd ed. Livingstone C, editor. Amsterdam: Elsevier science Ltd; 2002;315-20.

3. Welling PG, Dobrinska MR. Dosing considerations and bioavailability assessment of controlled drug delivery systems. In: Robinson JR, Lee VH, editors. Controlled drug delivery: Fundamentals and applications. 2nd ed. New York: Marcell Dekker Inc; 1987;253-89.

4. Brahmankar DM, Jaiswal SB. In: Biopharmaceutics and Pharmacokinetics a treatise. 1st ed. Jain MK, editor. Delhi: Vallabh Prakashan; 2003;335-71.

5. Chein YW. Novel Drug Delivery Systems. $2^{\text {nd }}$ ed. New York: Marcel Dekker. Inc. 1992;1-139.

6. Lee TW, Robinson JR. Controlled-release drug-delivery systems. In Gennaro A, editor. Remington: The Science and Practice of Pharmacy, $20^{\text {th }}$ ed., Pennsylvania: Mack Publishing Company; 2001;903-329.

7. Aulton ME. Pharmaceutics: The Science of Dosage Form Design. $2^{\text {nd }}$ ed., Livingstone C. Elsevier science Ltd; 2002;315320.

8. Yasunori Sato, Yoshiaki Kawashima., Hirofumi Takeuchi, Hiromitsu Yamamoto. In vitro evaluation of floating and drug releasing behavior of hollow microspheres (microballoons)
$70.95 \%(\mathrm{C} 1-\mathrm{A})$ respectively. The percentage cumulative drug release of E1-A and $\mathrm{C} 1-\mathrm{A}$ at the end of $10 \mathrm{~h}$ were found to be $62.15 \%$ and $63.05 \%$ respectively. The data's obtained were compared respectively with that of E1 and $\mathrm{C} 1$. The results were almost similar and hence showed good reproducibility.

\section{CONCLUSION}

The formulation using Eudragit RL 100 and cellulose acetate showed a constant rate of release. Thus, prepared floating hollow microspheres of famotidine may prove to be potential candidates for a multiple-unit drug delivery device adaptable for any intragastric condition.

prepared by the emulsion solvent diffusion method. European Journal of Pharmaceutics and Biopharmaceutics 2004; 57:235 243.

9. The Merck Index edition 11;1962:302.

10. Handbook of Pharmaceutical exipients edition 2;362-366.

11. Garg S, Sharma S. Gastroretentive drug delivery systems. Business Brief Pharmatech $5^{\text {th }}$ edi., 2003.

12. Garg R, Gupta GD. Progress in controlled gastroretentive delivery systems. Tropical Journal of Pharmaceutical Research 2008;7:1055-1066.

13. Streubel A, Siepmann J, Bodmeier R. Floating matrix tablets based on low density foam powder effects of formulation and processing parameters and drug release. European Journal of Pharmaceutical sciences 2003;18:37-45.

14. Streubel A, Siepmann J, Bodmeier R. Floating microparticles based on low density foam powder. International Journal Pharmaceutics 2002;241:279-292.

15. Richard AK, Mohamed AA, Suchada Nilkumhang, Sudexshina Murdan, Abdul WB. Fabrication and in vivo evaluation of highly $\mathrm{pH}$ responsive acrylic microparticles for targeted gastrointestinal delivery. European Journal of Pharmaceutical Science 2009;37:284-90

16. Martin A. Micromeretics. Physical Pharmacy, Fourth Ed.Lea Febiger, and Philadelphia 1993;431-32.

17. The Merck Index edition 11;1962:302. Handbook of pharmaceutical excipients edition 2; 92. 